\title{
COMMON BILE DUCT STONES. Analysis of the videolaparoscopic surgical treatment
}

\author{
Marco Aurelio SANT0 ${ }^{1}$, Carlos Eduardo DOMENE ${ }^{1}$, Daniel RICCIOPP0 ${ }^{1}$, Lian BARREIRA ${ }^{1}$, \\ Flavio Roberto TAKEDA ${ }^{1}$ and Henrique Walter PINOTTI ${ }^{2}$
}

\begin{abstract}
Context - About 9\% of the Brazilian population has gallstones and the incidence increases significantly with aging. The choledocholithiasis is found around $15 \%$ of these patients, and a third to half of these cases presented as asymptomatic. Once the lithiasis in the common bile duct is characterized through intraoperative cholangiography, the laparoscopic surgical exploration can be done through the transcystic way or directly through choledochotomy. Objective - To evaluate the results and outcomes of the laparoscopic treatment of common bile duct lithiasis. Methods - Seventy consecutive patients were evaluated. They prospectively underwent the treatment of the lithiasis in the common bile duct and the exploration ways were compared according to the following parameters: criteria on their indication, success in the clearance, surgical complications. It was verified that about $1 / 2$ of the choledocholithiasis carriers did not show any expression of predictive factors (clinical antecedents of jaundice and/or acute pancreatitis, compatible sonographic data and the pertaining lab tests). The laparoscopic exploration through the transcystic way is favored when there are no criteria for the practice of primary choledochotomy, which are: lithiasis in the proximal bile duct, large (over $8 \mathrm{~mm}$ ) or numerous calculi (multiple calculosis). Results - The transcystic way was employed in about $50 \%$ of the casuistic and the choledochotomy in about $30 \%$. A high success rate (around $80 \%$ ) was achieved in the clearance of the common bile duct stones through laparoscopic exploration. The transcystic way, performed without fluoroscopy or choledochoscopy, attained a low rate of success (around $45 \%$ ), being $10 \%$ of those by transpapilar pushing of calculi less than $3 \mathrm{~mm}$. The exploration through choledochotomy, either primary or secondary, if the latter was performed after the transcystic route failure, showed high success rate (around 95\%). When the indication to choledochotomy was primary, the necessity for choledochoscopy through choledochotomy to help in the removal of the calculi was 55\%. However, when choledochotomy was performed secondarily, in situations where the common bile duct diameter was larger than $6 \mathrm{~mm}$, the use of choledochoscopy with the same purpose involved about $20 \%$ of the cases. There was no mortality in this series. Conclusion - The laparoscopic exploration of the common bile duct was related to a low rate of morbidity. Therefore, the use of laparoscopy for the treatment of the lithiasis in the common bile duct depends on the criteria for the choice of the best access, making it a safe procedure with very good results.
\end{abstract}

HEADINGS - Choledocholithiasis. Laparoscopy. Cholangiography.

\section{INTRODUCTION}

The occlusion of the biliary tract is the most important phenomenon in biliary illness. It can be said that with the compromise of the main biliary tract, affections initially of the gallbladder, a local process, convert into systemic disease ${ }^{(39)}$. Calculosis of the hepatocholedochus constitutes a particularly important aspect of biliary lithiasis, not only due to its high incidence, but also for the severity of its complications and for the various treatment options ${ }^{(55)}$. Acute suppurative cholangitis and acute biliary pancreatitis are conditions in which the major cause are bile duct stones, and both are potential lethal conditions in its severe forms ${ }^{(81)}$.

Epidemiological studies indicate that approximately $10 \%$ to $15 \%$ of the adult population in United States of America contains calculi in the gallbladder, estimating approximately one million cases diagnosed yearly ${ }^{(58)}$. In Brazil, a study demonstrates prevalence of gallbladder

\footnotetext{
No conflicts of interest.

${ }^{1}$ Departmento de Gastroenterologia, Faculdade de Medicina da Universidade de São Paulo, SP, Brasil; ${ }^{2}$ In Memoriam.

Correspondence: Dr. Daniel Riccioppo - Rua Doutor Barachisio Lisboa, 88 - 05441-090 - São Paulo, SP, Brasil. E-mail: danriccioppo@uol.com.br
} 
lithiasis in $9.3 \%$ of the general population ${ }^{(13)}$. This coefficient rises from $2.4 \%$ to $27.5 \%$ when comparing the age groups of 20 to 29 and 70 and over, respectively. In women over 50 years of age this value is superior to $20 \%$.

The historical incidence of choledocholithiasis has been estimated at approximately $15 \%$, with reports varying from 7 to $22 \%(3,6,14,54,55)$. The lower current incidence, approximately $7 \%$, varying from $3 \%$ to $10 \%$ of those afflicted by gallbladder lithiasis, is explained based on larger availability of diagnosis and precocious referral to surgical therapeutics, especially laparoscopic cholecystectomy $^{(3,7,21)}$. Perhaps, the less frequent application of intraoperative cholangiography in the videolaparoscopic era may underestimate this occurrence ${ }^{(47,67,78)}$. A German study found that only $6 \%$ of institutions perform routine transoperative cholangiography during laparoscopic cholecystectomy, while 7 times more hospitals do not ${ }^{(53)}$.

In Brazil, in a multicenter study to evaluate the results obtained with laparoscopic cholecystectomy in 33,563 cases, lithiasis in the main biliary tract was diagnosed in approximately 1,400 cases, or $4.2 \% 0^{(72)}$.

Despite attempts in literature to use predictors to perform selective intraoperative cholangiography ${ }^{(20)}$, approximately $30 \%$ to $50 \%$ of the common bile duct stones cases present themselves in an unsuspicious manner, given the low pinpointing capacity of the commonly used tests in the preoperative evaluation of patients programmed for cholecystectomy. This emphasizes the role of routine intraoperative cholangiography as the only way to establish diagnosis in these circumstances ${ }^{(35,49,65)}$.

Classically, the surgery by laparotomy for access to the main biliary tract constituted the standard treatment for choledocholithiasis, preceding choledocholithotomy and external biliary drainage ${ }^{(80)}$. In the 70's, the introduction of the retrograde endoscopic cholangiography and subsequently papillotomy permitted a therapeutic alternative, especially in those patients that had previously been subject to cholecystectomy ${ }^{(12,17,23,44)}$.

With the advent of videolaparoscopic surgery, the endoscopic approach became an important complementary procedure, recommended in the preoperative, when used for the diagnosis of choledocholithiasis, as well as in the postoperative period ${ }^{(9,32,34,46)}$. The central reasons for this behavior were the absence of satisfactory techniques for the laparoscopic exploration of the biliary tract or the restriction of its practice to a few centers, as well as the surgeon's desire to avoid conversion to laparotomy ${ }^{(3,30,46,69)}$.

As experience with the laparoscopic access accumulated, associated with technological developments that made available more delicate instruments and enabled choledochoscopy with a flexible device, the surgical exploration of the biliary tracts through this access became a reality ${ }^{(61,66)}$. The possibility of complete extraction of the calculi in a single operative procedure, avoiding manipulation of the papilla by endoscopic procedures and its consequences, progressively turned this technique in a more utilized procedure ${ }^{(4,24,76)}$.

Upon deciding on the usage of videolaparoscopic surgical exploration, it is fundamental to establish the strategy, which includes analysis of local conditions and interpretation of the intraoperative cholangiography images, to decide the type of access to the main biliary tract, either through the transcystic access or directly through choledochotomy ${ }^{(25,36)}$.

Then, the objective of the present study is to evaluate the outcome of videolaparoscopic surgical exploration of the biliary tract, for treatment of common bile duct stones, taking into consideration the transcystic and the transcholedochus accesses. This evaluation consists of the analysis of the following parameters: criteria for indication, success in the clearance of biliary lithiasis, and surgical complications.

\section{METHODS}

The study included 70 consecutive patients that were submitted, in a prospective manner, to videolaparoscopic cholecystecomy and treatment of common bile duct stones.

They were admitted into the Division of Clinical Surgery II - Department of Digestive Tract Surgery of the Hospital das Clínicas, University of São Paulo Medical School, São Paulo, SP, Brazil, over a period of 6 years.

The total number of patients with common bile duct stones corresponds to $3.53 \%$ of the global casuistic of 1,979 patients submitted to videolaparoscopic cholecystectomy for cholelithiasis in the same period. Intraoperative cholangiography was performed in $90.95 \%$ of the total number of patients.

The study was approved by the Ethics and Research Commission of the Department of Gastroenterology of the University of São Paulo Medical School and all patients having been properly informed about the videolaparoscopic surgical procedure, especially in what concerns the possible conversion to an open intervention.

The mean age was 51.6 years, varying from 20 to 85 years. Fifty-three patients were female and 17 male, corresponding to $75.7 \%$ and $24.3 \%$, respectively. The mean weight was 65.9 kilograms, varying from 44 to 100 kilograms. The mean height was 1.59 meters, varying from 1.41 to 1.82 meters.

The choice of the surgical procedure to be adopted was based on criteria dependent on the interpretation of the intraoperative cholangiography. Depending on radiological criteria, indication of primary choledochotomy or transcystic access was done. When diameter of the calculi present in the main biliary tract was larger than $8 \mathrm{~mm}$ (in the smallest axis when deformed), or larger than 2 to 3 times the diameter of the cystic duct, when location of calculi was in the main biliary tract proximally to the insertion of the cystic duct (common hepatic duct), or in cases of multiple calculosis, the approach by choledochotomy was preferred.

Indication of exploration through transcystic access was preferential when choledocholithiasis that does not present with any indication for exploration through primary choledochotomy, as described above.

Special circumstance, for which previously defined conduct can not be established, constitutes the finding of impacted calculus close to the duodenal papilla. In this situation, when dilation of the main biliary tract can not be observed, normally because of small calculus, the transcystic access can be attempted, aiming for its distal transpapillary displacement. 
On the other hand, when biliary dilation is already present, usually by larger calculi, other therapeutic approaches can be endeavored, including transcholedochus exploration.

\section{Surgical technique for exploration of the main biliary tract}

The instrumental exploration of the biliary tract, either through the transcystic or transcholedochus accesses, requires the puncture of the abdominal wall with a metallic cannula with a diameter of $2.5 \mathrm{~mm}$, enabling the introduction of specific instruments into the abdominal cavity for extraction of calculi. The optimal position of this cannula is the middistance between the epigastric and right hypochondriac trocars, projecting itself perpendicularly over the biliary tract. When performing the choledochoscopy, an additional $5 \mathrm{~mm}$ trocar is introduced in that region.

The instrumental manipulation through transcystic access is performed through an incision in the cystic duct made for the intraoperative cholangiography. The adequate dilation of the cystic duct is necessary, normally obtained by the passage of a Fogarty $^{\circledR}\left(\right.$ Baxter $\left.^{\circledR}\right)$ catheter, available in the diameters 4, 5 and 6 Fr, which, after insufflation of the balloon, is slowly tractioned until its exteriorization in the cystic duct orifice, repeating the maneuver several times until the degree of dilation necessary for the unrestricted introduction of the catheter is obtained. In some situations the widening of the orifice can be achieved through the prolongation of the longitudinal and distal incisions of the cystic duct.

Through the transcystic access there are two techniques for the manipulation of the main biliary tract. With mechanic extraction with capture, the complete extraction of calculi is obtained through capture with basket type probes (Figure 1). In transpapillary forced migration, clearance is obtained by the migration of calculi through transpapillary displacement, utilizing anti-spasmodic drug by intravenous infusion (scopolamine bromide, $20 \mathrm{mg}$ ) to relax the sphincter of Oddi, followed by the rapid instillation of saline through the transcystic plastic catheter used for intraoperative cholangiography, or through the actual push by means of the Fogarty catheter $(4,5$ or 6 Fr catheter, with a number chosen based on the gauges of the cystic duct and common bile duct) or basket type probe. This therapeutic method is only attempted in circumstances in which the choledochus is not dilated, containing calculi with diameter up to $3 \mathrm{~mm}$, preferably isolated in the distal portion.

Through a choledochotomy, success of the clearance can be obtained by means of three techniques of manipulation of the main biliary tract. To achieve this, it is necessary to expose the anterior portion of the choledochus through the dissection of the peritoneal layer that covers this area, with medial displacement of the hepatic artery, or its branches, in some situations. The transverse choledochotomy is used, with the approximate extension of the largest diameter of the calculi shown by cholangiography. After section of the biliary tract and outflow of its contents, a small gauze plug, whose extremity is tied to a cotton thread, which facilitates its removal, is inserted through the proximal orifice (Figure 2).
This maneuver prevents the migration of cranial calculi or fragments when manipulating the distal segment of the choledochus.

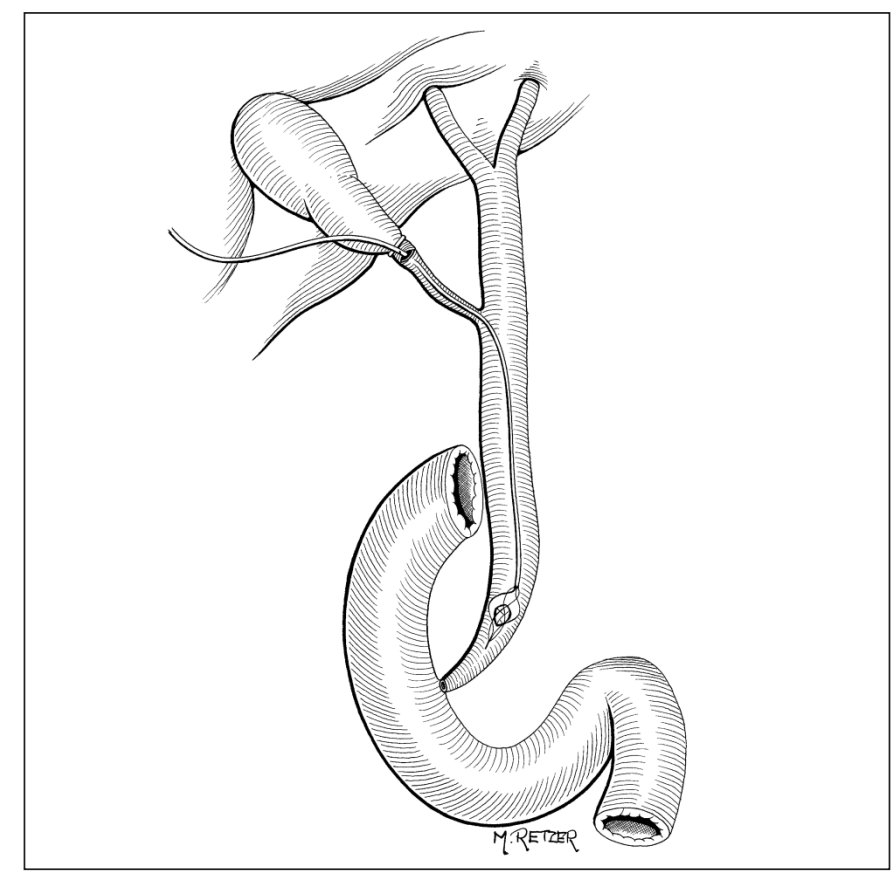

FIGURE 1. Capture of calculi with "basket" type probe introduced through the cystic duct

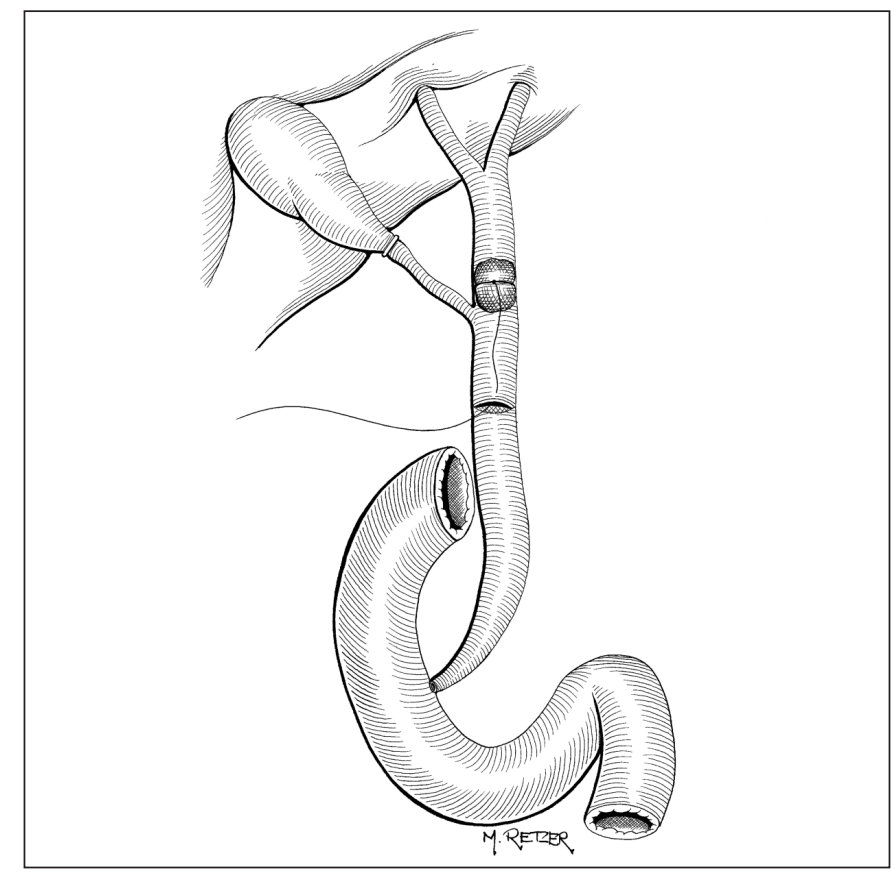

FIGURE 2. Transverse choledochotomy and the insertion of the gauze plug in the proximal segment 


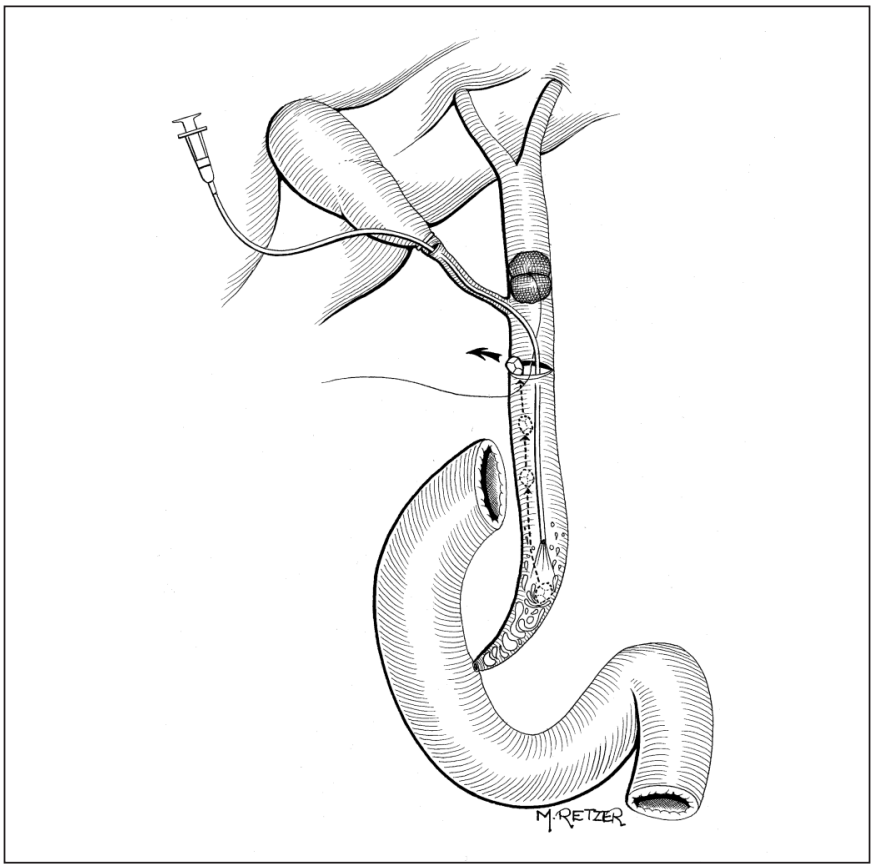

FIGURE 3A. Mixed technique for calculi extraction through choledochotomy - extrusion of calculi by fluid turbulence

The transcholedochus exploration is performed primarily, following criteria for indication already mentioned, or secondarily, following an unsuccessful transcystic exploration. For this condition it is necessary that the size of the choledochus be greater than $6 \mathrm{~mm}$. In order to assess the implications of the indications for determination of efficiency of this technique, the success rate among patients with primary and those with secondary indication for choledochotomy was compared. The results of application of each type of technique were also compared in relation to the groups that realized the choledochotomy primarily or secondarily.

Different techniques also can be mixed, involving the use of the following procedures, alone or combined. Immediately after the choledochotomy, the rapid infusion of saline, usually through the plastic catheter used for intraoperative cholangiography inserted through the cystic duct, allows the mobilization and subsequent cleaning of calculi, with removal through the opening in the choledochus (Figure 3A). Next, additional mobilization is achieved with the Fogarty catheter, also allowing the removal of calculi (Figure 3B). Finally, by basket type probe approach, calculi capture and extraction through choledochotomy is attempted (Figure 3C). In some situations, not all three procedures are necessary.

To perform a direct visualization of the common bile duct, a flexible choledochoscope is used, with a caliber of $5 \mathrm{~mm}$, coupled to a second video monitor; it contains an internal work channel of $2 \mathrm{~mm}$, through which you can insert pressure clamps and Fogarty or basket type probes. Thus, the visibility inside the main biliary tract, proximal and distally, may be required for the extraction of calculi (choledochoscopy for extraction), or simply to control the clearance after surgical manipulation

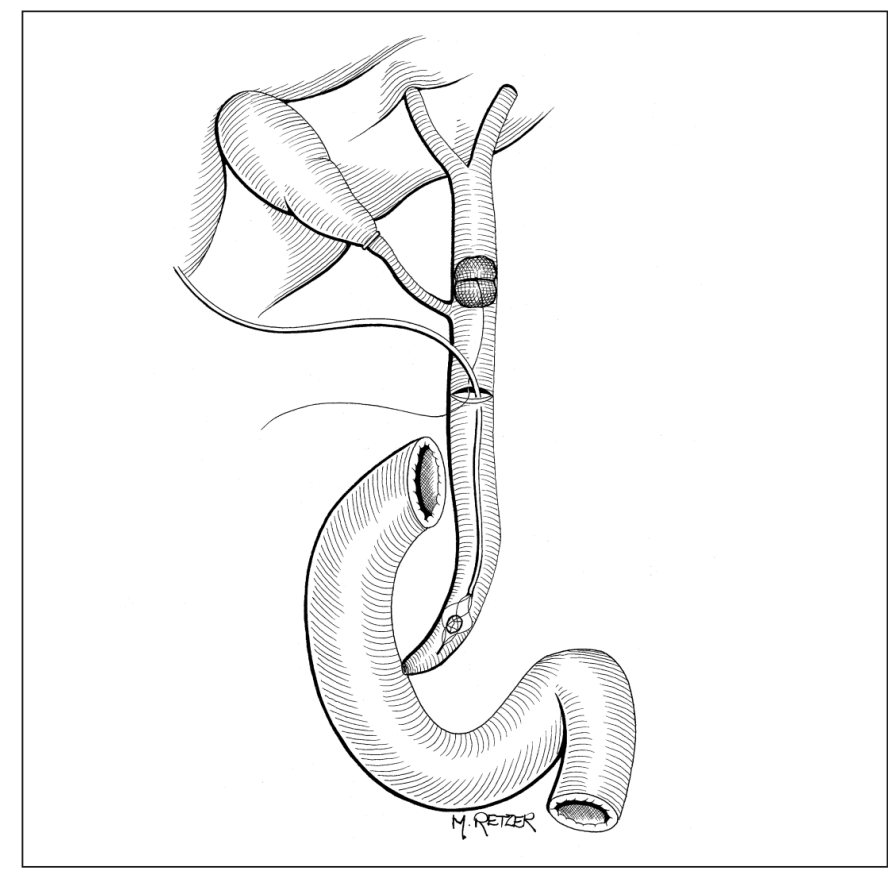

FIGURE 3B. Mixed technique for calculi extraction through choledochotomy traction of the catheter after inflation of the balloon and dragging of calculi

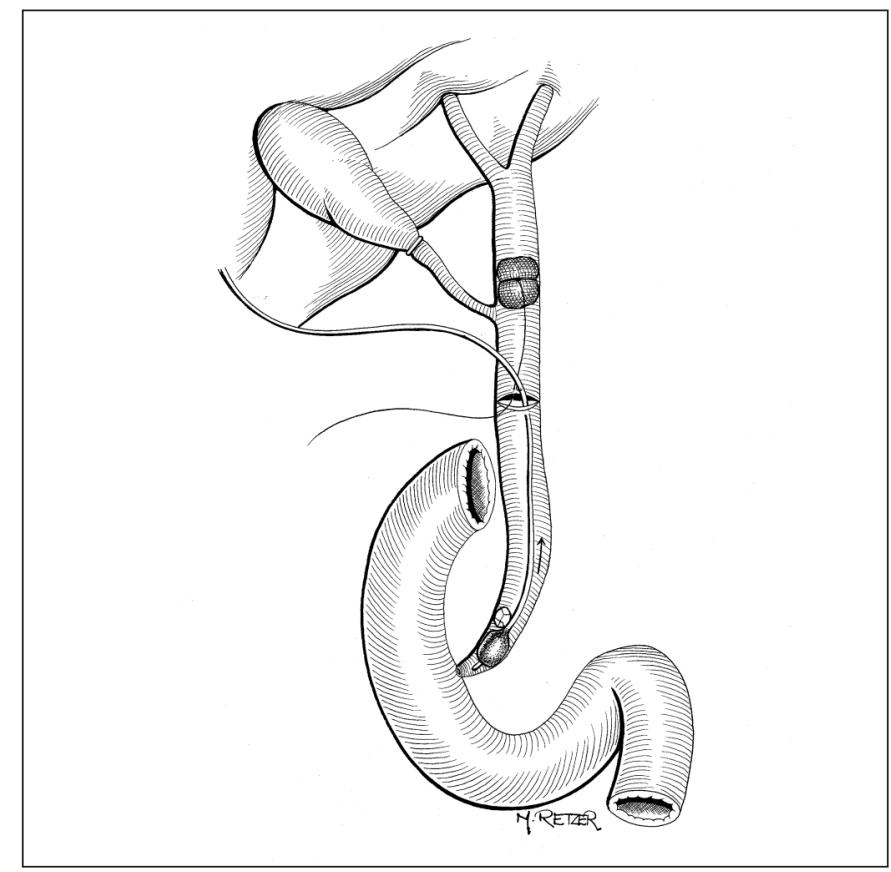

FIGURE 3C. Mixed technique for calculi extraction through choledochotomy - capture of calculi with "basket" type probe

(choledochoscopy for control) (Figure 4). Manipulation probes can be inserted via the choledochoscope's work channel or directly through the choledochotomy, in this case allowing for the use of larger caliber probes. Choledochoscopy is most commonly used after failure of the mixed technique. 


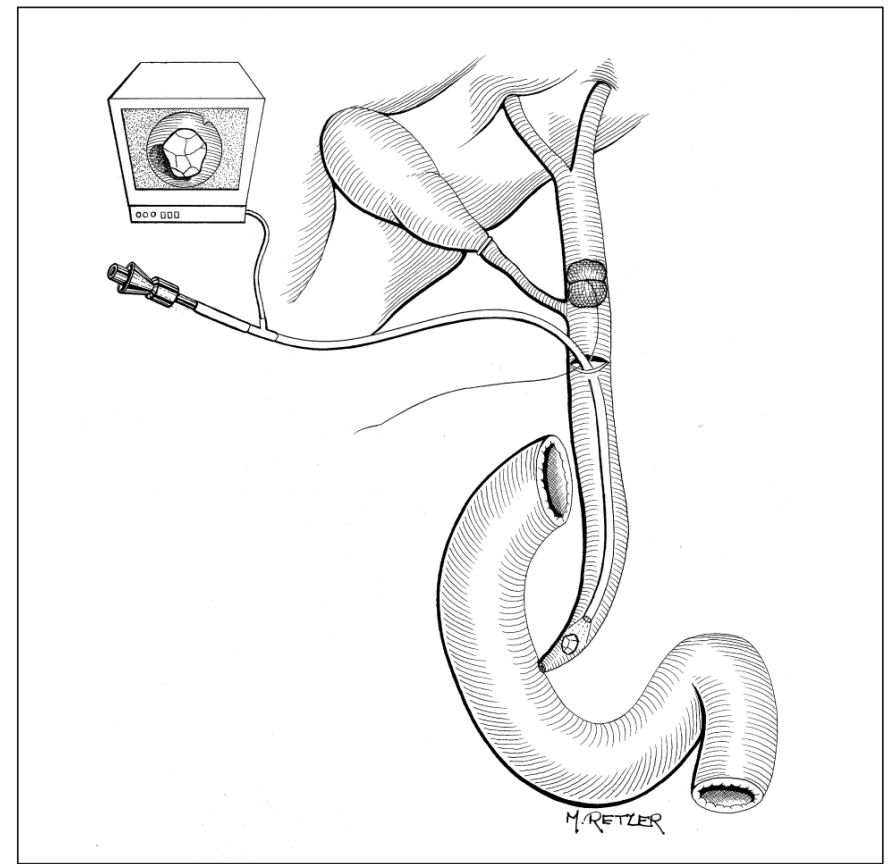

FIGURE 4. Choledochoscopy of the distal segment

The external drainage of the biliary tract after transcystic exploration is used exceptionally, only upon the poor drainage of the contrast to the duodenum even after intravenous infusion of the anti-spasmodic (scopolamine bromide, $20 \mathrm{mg}$ ). When necessary, it is done by the plastic catheter used for intraoperative control cholangiography, secured by double clamping with metallic clip or non absorbable thread and exteriorized in the right flank of abdomen.

On the other hand, in transcholedochus exploration, in a routinely fashion, it is followed by the external biliary drainage through a Kehr drain, having both branches of the transversal loop at about $2 \mathrm{~cm}$ each. The long branch of the drain can be exteriorized directly through choledochotomy, or through the cystic duct. In the latter situation, the surgical suture of the choledochus becomes easier, feasible with separate stitches or continuous suture with 5-0 absorbable thread, having the long branch fixed to the cystic stump with no absorbable thread, avoiding strangulation (Figure 5).

Subsequently, the intraoperative control cholangiography is performed with injection of contrast material into the Kehr drain, evaluating the success in the clearing of lithiasis, proper positioning of the drain, any eventual leakage through the surgical suture of the choledochus and drainage of the contrast material to the duodenum. The long branch of the drain is exteriorized to the right hypochondrium region, usually at the point of insertion of the metal cannula through which the probes to manipulate the biliary tract are inserted, which coincides with the area of insertion of the trocar when the choledochoscopy is performed.

The external biliary drainage can also be performed by means of a plastic catheter inserted through the cystic duct.

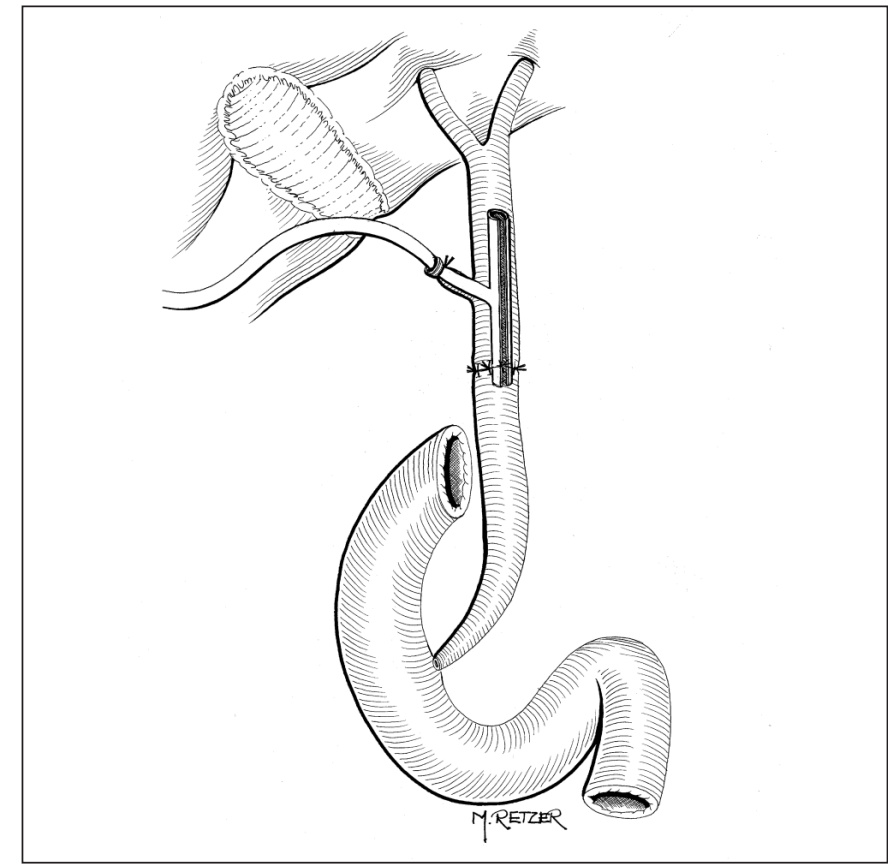

FIGURE 5. External drainage of the biliary tract through the Kehr drain

In special circumstances, where local conditions permit safe suture of the choledochus and intraoperative control cholangiography demonstrates success in clearing the lithiasis, as well as the satisfactory drainage of the contrast material to the duodenum, the external drainage may be abdicated, simply by removing the plastic catheter and occluding the cystic duct.

\section{RESULTS}

The indication for transcystic exploration occurred in 37 patients. The choledochus presented normal caliber in 20 of these patients, being dilated, with caliber above $6 \mathrm{~mm}$, in the remaining 17. All calculi were found in the distal choledochus, and in 4 patients were smaller than $3 \mathrm{~mm}$ and positioned close to the duodenal papilla, not determining, however, dilation of the biliary tract.

The indication for primary transcholedochus exploration occurred in 20 patients. All of the patients in this groups exhibited choledochus caliber superior to $6 \mathrm{~mm}$. In 12 patients the indication was exclusively resulting of large calculi. However, the indication because of proximal localization of calculi occurred in 3 patients. Multiple calculosis induced this procedure in 2 patients. Three patients submitted primarily to choledochotomy displayed, in the intraoperative cholangiography, image of an impacted calculus in the duodenal papilla.

The endoscopic treatment was opted for in nine patients, in which five were in the preoperative period and four in the postoperative, without any surgical intervention of the biliary tract in the course of the cholecystectomy. 
In two patients, given the presence of undiagnosed great dilation of the biliary tract associated with multiple calculosis, the implementation of a biliary bypass through choledochalduodenal anastomosis was opted for.

In two patients in whom intraoperative cholangiography revealed image suggestive of lithiasis, with small calculus close to the duodenal papilla, together with a choledochus of small caliber, raising questions as to the real presence of the calculus, expectant conduct was adopted, without instrumental manipulation of the biliary tract, but with external drainage of the same through a plastic catheter exteriorized by the cystic duct itself.

\section{Success in the clearance of the biliary tract}

Among the 37 patients that underwent transcystic exploration, success was achieved in clearing of the biliary tract in 16 patients $(43.2 \%)$, out of which four were submitted to transpapillary displacement through forced transcystic migration due to the presence of calculi $<3 \mathrm{~mm}$ and choledochus without dilation. In 21 patients, after unsuccessful attempts through transcystic manipulation, direct manipulation of the biliary tract through the choledochotomy was opted for in 11 patients, whereas postoperative endoscopic therapy was attempted in 8 patients, and conversion to laparotomy in 2 patients.

Among the 31 patients undergoing videolaparoscopic transcholedochus surgical exploration, 20 of them primarily and 11 secondarily after failure of transcystic exploration, success was obtained in clearing the biliary tract in 29 patients $(93.5 \%)$. In 2 patients among the 20 with primary indication to choledochotomy, conversion to laparotomy was required. The use of mixed technique was successful in 7 patients $(35 \%)$ and choledochoscopy was necessary in 11 patients (55\%). Among the 11 patients with secondary indication for choledochotomy, success with the mixed technique occurred in 9 patients $(81.8 \%)$ and choledochoscopy was necessary in 2 patients $(18.2 \%)$. Comparing the two groups of indication for choledochotomy, it was observed that the choledochoscopy was most needed in patients with primary indication, while in those in which the transcholedochus exploration was performed secondarily the mixed technique was sufficient to resolve the majority of cases $(P=0.024)$.

\section{Drainage of the biliary duct}

Among the 16 patients that underwent exclusive transcystic exploration, the external biliary drainage was used in 7 of them. The drain used was the same plastic catheter of the intraoperative cholangiography (intra-cath), exteriorized through the cystic duct and secured by two metallic clips or thread.

For those that underwent choledochotomy, in 5 cases primary suturing without external biliary drainage was performed. In the other 24 , transcystic drainage via intracath was used in 10 patients, a Kehr's drain exteriorized through the cystic duct in 9 , and the remaining 5 patients also received a Kehr's drain, however exteriorized by the choledochotomy itself.

\section{Complications}

There were no deaths in this casuistic.

Among the patients who underwent transcystic surgical exploration there was one case of perforation of the choledochus, retro-duodenal portion, whose detection was evidenced by leakage of the contrast material during the control intraoperative cholangiography post instrumental manipulation with basket type probe. It was then opted to precede the conversion to laparotomy with identification of the lesion in the posterior face of the choledochus, applying suture with absorbable thread (two separate sutures). Subsequently, transverse choledochotomy was performed on the supraduodenal portion, with the introduction of a Kehr's drain, exteriorized by the cystic duct, and followed by suture of the choledochus with separate sutures with absorbable thread. There were also three cases of hyperamylasemia and another case of premature displacement of the external biliary drain (transcystic intra-cath) in the 4th postoperative day, not resulting in any clinical complications.

In patients that underwent transcholedochus exploration, there were three cases with complications. In one case, in the 1st postoperative day, the patient developed toxemia and output of biliary secretion through the Penrose drain, being re-submitted to laparoscopy with discovery of choleperitoneum and fistula of the suture of the choledochus; this was followed by cleaning of the cavity, closing of the point of leakage, drainage of the cavity and maintenance of biliary drainage, with satisfactory postoperative evolution. In one patient, premature displacement of external biliary drain was observed, evolving with biliary fistula and satisfactory clinical control. In one case, 3 days after the scheduled withdrawal of the biliary drain (21st postoperative day), the patient presented pain in right hypochondrium, the ultrasound examination revealing presence of sub-hepatic collections, and the patient was maintained under clinical control with satisfactory evolution. There were five cases of transient hyperamylasemia without clinical manifestation.

\section{DISCUSSION}

The biliary lithiasis with unsuspicious presentation corresponded to about one-third of our casuistic, with patients that showed any signs, either clinical, laboratory or sonographical, of the impairment of biliary tract.

Previous studies showed high incidence of unsuspicious lithiasis in the main biliary tract (about $40 \%$ of patients with choledocholithiasis) and highlighted the conduct of routine use of intraoperative cholangiography to widen the possibility for this diagnosis; in addition, this method has other advantages, such as the study of the anatomy of the biliary tract ${ }^{(51,65)}$.

On the other hand, some authors advocate that unsuspicious biliary lithiasis is infrequent, especially in individuals under 60 years of age ${ }^{(41,42)}$. Attempt to validate scores obtained from the combined analysis of various factors were made, based on the belief that these indexes were useful to support the indication of preoperative endoscopic evaluation or to whether or not employ the intraoperative cholangiography $(5,38,40,42,71)$. 
In a study of 959 cholecystectomies with intraoperative cholangiography, 46 patients $(4.8 \%)$ had filling deffects in choledocus or common hepatic duct. In these cases, the cholangiogram catheter was held in place, and cholangiogram was repeated subsequently, and after 48 hours $26 \%$ of these patients had normal cholangiogram. Another $26 \%$ had normal exam at 6 weeks. According to this results the incidence of choledocholithiasis with potential for long-term morbidity is less than $2.5 \%{ }^{(15)}$. However the authors do not focus the potential risk of early postoperative complications related to choledocholithiasis.

High definition and elevated accuracy examinations, such as magnetic resonance cholangiography and endoscopic ultrasonography, would establish, preoperatively, the diagnosis of choledocholithiasis in almost all cases, even in non-dilated ducts ${ }^{(1,22,28)}$. But their high cost impedes their common use $\mathrm{e}^{(7,69)}$.

\section{Choice of technical procedure}

The complexity of the therapeutic approach of choledocholithiasis is evidenced by the many therapeutic propositions.

In 1993, a consensus meeting sponsored by the National Institute of Health of the USA supported all forms of well-established treatment of lithiasis in the main biliary tract: laparotomy, laparoscopy and endoscopy, including the expected conduct in special circumstances, highlighting the role and perspective that the laparoscopic access had acquired $^{(37)}$.

A multi-centric study conducted in Brazil demonstrates this complexity ${ }^{(72)}$. The endoscopic approach, pre or postoperative, represented the main form of treatment for choledocholithiasis, as it was used in about $55 \%$ of cases, while videolaparoscopy was used in about $33 \%$ of cases, and laparotomy to approximately $12 \%$.

This scenario implies that the treatment of these patients should be individualized, considering the patient's clinical conditions, the characterization and timing of diagnosis of the lithiasis, the surgical experience, and resources of the institution ${ }^{(7,21,27,50)}$. Recognizing limits is the basis for working together and establishing the actual indications for different methods of treatment of biliary calculi.

The criteria to select the transcystic or transcholedochus access are based on analysis of cholangiography characteristics of the biliary tract and calculi present. The transcystic exploration is, in principle, always used, reserving choledochotomy for special circumstances or upon failure of the former ${ }^{(8,63)}$.

The transcholedochus approach is preferential when large gallstones are present. The transcystic extraction of big calculi, larger than $8 \mathrm{~mm}$ or disproportionate to the caliber of the cystic duct, involves great risk of laceration of the cystic-choledochus junction. The difficult access to calculi proximal to the insertion of the cystic duct through the cystic duct itself, also excluding the transcystic path as real option. Finally, the large possibility of residual calculosis after transcystic exploration of the main biliary tract occupied by numerous calculi, and the difficulty in controlling the clearance, requires transcholedochus access as the primary option in multiple calculosis.

In our series of 70 patients, the videolaparoscopic exploration was indicated in 57 cases, or $81.5 \%$ of total. The transcystic route represented $52.8 \%$ of patients, while the transcholedochus route, $28.7 \%$.

In a multi-institutional series of 226 patients, videolaparoscopy through the transcystic route was used in $83 \%$ of cases, and transcholedochus in the other $17 \%{ }^{(6)}$. A choledochus caliber larger than $6 \mathrm{~mm}$ is a secure guarantee for the implementation of choledochotomy, particularly with regard to the instrumental manipulation of biliary tract, with inherit risk for lacerations and mainly because of the possibility of stenosis after suture of the choledochus ${ }^{(67,69)}$. The preference for transverse incision is made on the basis of lesser compromise of choledochus blood irrigation as well as the smaller possibility of narrowing after suture of the choledochus. The longitudinal incision of the choledochus is preferred by some surgeons because it allows easy access for the insertion of the choledochoscope, and it can be more easily extended ${ }^{(7,60)}$.

The direct approach of the biliary tract should be avoided when intense inflammatory process is found in the hepatic hilum due to difficulties in dissection and possibility of bleeding from larger vessels ${ }^{(36,62,63)}$.

Literature data supports the idea of advantages in treatment of cholelithiasis and common bile duct stones in a one-stage procedure ${ }^{(74)}$. The endoscopic sphincterotomy up to 48 hours after cholecystectomy is associated with acute pancreatitis within $30 \%$ of procedures and up to $0.6 \%$ of patients will develop pancreatic necrosis. This serious complication is related to mortality rate of $0.4 \%$. The postoperative endoscopic approach, anyway, is established as an option for the treatment of choledocholithiasis, is a procedure commonly used in clinical practice, constituting as an alternative to conversion to laparotomy, although adding considerable cost and risk ${ }^{(31,52,75)}$.

Some favorable factors for postoperative endoscopic exploration are admitted, such as: small non-obstructive calculi, thin biliary tract and therefore with the possibility of stenosis due to surgical manipulation, and patients at risk for prolonged operations. The presence of intense inflammatory process in the gallbladder, extending to the region of the hepatic hilum, for bringing bigger technical difficulties and possible complications of the surgical operation, is also a favorable circumstance for postoperative endoscopic approach.

One of the major concerns about the postoperative endoscopic therapy is its potential failure and consequences in this phase. The external biliary drainage through a transcystic catheter in order to facilitate the endoscopic procedure is often used ${ }^{(60,69,78)}$. The best placement of this catheter is intra-choledochus, not surpassing the duodenal papilla. The fear of catheters surpassing the papilla comes from the risk of obstruction of the pancreatic duct and consequent acute pancreatitis. But it is admitted that the risk of pancreatitis is low, based on experience of placement of stents by endoscopy. 
The indication for biliary bypass is favored when severe compromise of the choledochus is present, evidenced by large biliary dilation and severe difficulty in transpapillar emptying in intraoperative cholangiography, especially if associated with multiple calculi ${ }^{(29)}$. One should not, however, indicate it too often, since the intensity of the inflammatory process, preferably chronic, present in the wall of choledochus is not linked to their degree of dilation and therefore do not constitute irreversible changes ${ }^{(10)}$. The possibility of achieving safe choledochus-duodenal anastomosis by videolaparoscopy made it the most used technique for biliary bypass ${ }^{(19,26)}$, being employed in two patients in our casuistic, precisely because they presented large dilations of the choledochus, one of which with multiple calculi. The minimum choledochus caliber highlighted, to perform safe anastomoses, in order to ensure adequate permeability and avoid the complications arising from possible stenosis, is $16 \mathrm{~mm}^{(29)}$.

A prospective study found recurrent choledocholithiasis rate of $10.1 \%$ in 169 patients who were previously treated with choledocholithotomy and T-tube drainage (including laparoscopic approach) or endoscopic sphincterotomy, for common bile duct stones, and monitored for a mean period of 9.6 years. In this same study the 44 patients who undergone choledochoduodenostomy for the purpose of preventing choledocholithiasis recurrence were followed for the same period have no recurrence ${ }^{(45)}$.

The possibility of false-positive images, as well as the possibility of spontaneous migration of small calculi, supports the expected conduct in the situation of doubt in diagnosis. Surgical exploration is not carried on in these cases, neither transcystic nor transcholedochus, with the convenience of external biliary drainage through a transcystic catheter to allow subsequent re-evaluation by postoperative control cholangiography. In two patients, in whom this practice was established in our study, the postoperative control cholangiography did not confirm choledocholithiasis. In the case of diagnostic doubt, the external biliary drainage may be the best option because it allows the possible postoperative diagnostic confirmation, and if so, helps the additional endoscopic procedure ${ }^{(31)}$. The risk to treating calculi less than $3 \mathrm{~mm}$ must be balanced with the risk of arising complications ${ }^{(80)}$. Treatment in such cases should only be indicated in those with history of acute biliary pancreatitis. The risk of exploratory procedures of the biliary tract, either by laparoscopy or endoscopic, may be higher than the expectant conduct, and more studies are necessary to define the safety of this practice in these conditions. However, many cases of acute pancreatitis are results of "probably insignificant" calculi abandoned in the biliary tract ${ }^{(43)}$.

\section{Success in clearing the biliary tract}

The success rate in our casuistic using the transcystic access was around $50 \%$. The technical method of forced migration was attempted, given that the criteria for indication including small calculi and no biliary dilation, in approximately $10 \%$ of cases, achieving success in all of them.
A wide study brings us an overview of this point. Although they have obtained a success rate around $80 \%$, about $40 \%$ of these successes were achieved by the technical method of forced migration or irrigation, denoting the presence of small calculi, or even suspected, in a significant contingent of patients ${ }^{(6)}$.

The use of a $3 \mathrm{~mm}$ scope via transcystic duct allows the surgeon to perform a more complete and direct visual exploration of the common duct system, increasing the chances of successful treatment ${ }^{(2)}$. However, it remains the exception limitations of this approach even with the use of scope, where success will also depend fundamentally on the size of calculi and diameter of the cystic duct.

The transcholedochus exploration achieved, in our study, overall success rates of around $93 \%$, being $90 \%$ and $100 \%$ in those undergoing choledochotomy primarily and secondarily, respectively. No significant difference between rates of success was found, showing that even with more complex circumstances, primarily indicative of transcholedochus approach, satisfactory success rates are achieved.

A review of studies of exploration by choledochotomy, gathered 25 patients in which the success rate was of $96 \%(60)$.

In our series the endoscopic therapy was successful in all patients with whom it was employed, either in pre or postoperative phase. However, the success rate with this procedure has been described to be around $90 \%$. If presented with the impossibility of endoscopic removal of the calculi, especially with large calculi, a biliary stent can be employed to avoid impaction and maintain the duct pervious until the definitive solution is reached ${ }^{(70)}$.

However, in isolated studies, not related to reference centers, there are lower rates of success ${ }^{(16,18)}$. The results of endoscopic procedures vary according to the experience of the endoscopic team and selection of patients, indicating the success rate of clearance of $65 \%$ in some series, with report of a success rate of $56 \%$ and $91 \%$ during pre and postoperative procedures, respectively ${ }^{(64)}$.

In a randomized study comparing laparoscopic exploration to postoperative endoscopic treatment, a success rate of $75 \%$ after the first intervention in both procedures was identified. With the completion of two or three endoscopic attempts, the success achieved for this group was around $93 \%{ }^{(67)}$. Approximately $10 \%$ to $15 \%$ of patients require more than one endoscopic session to complete clearance of choledocholithiasis ${ }^{(48)}$. It is also important to consider the possibility of residual calculi, approximately $3 \%$ to $10 \%$, after the endoscopic procedures ${ }^{(11,57)}$. When the postoperative endoscopic therapy does not achieve success and as an alternative to reoperation, other conservative methods can be used, such as extra-corporeal lithotripsy ${ }^{(73)}$.

In a review about this theme, the authors addressed an interesting point of view. In pre-minimally invasive surgery era, there was any study showing advantages in endoscopic sphincterotomy before open cholecystectomy over conventional open choledocholithotomy ${ }^{(79)}$. It seems that this discussion was started due to technical difficulties encountered in the early experience with laparoscopy. 


\section{Complications}

The biliary fistulas are complications of bile duct closure; they may be the result of unclenching of the clip for occlusion of the cystic duct, or directly from the suture of the choledochus, clinically manifesting itself by bile leakage and formation of intra-abdominal collections. The formation of intra-abdominal collection is possible, if the cavity drainage is insufficient, being the computerized tomography as the best method for diagnosis.

Clinical support treatment is sufficient as an adequate solution for most cases, provided that no maintaining factors exist, such as difficulty in biliary drainage. In these situations, additional treatment should be established, in particular the endoscopic approach ${ }^{(56)}$. The early biliary fistula, which results in choleperitoneum with acute abdomen, should be treated surgically ${ }^{(77)}$.

In our series one case of biliary fistula occurred, originating from the suture of the choledochus, expressed in the first postoperative day by leakage of bile through the drain cavity. Given the association of clinical signs of toxemia and peritoneal irritation, re-laparoscopy was indicated, with favorable postoperative evolution.

However, the occurrence of biliary fistula after laparoscopic exploration of the biliary tract is small, below $2 \%$. Originating from the cystic duct, fistula was reported in $1.3 \%$, arising from the detachment of the clip for occlusion of the cystic duct, treated conservatively ${ }^{(59)}$. The possibility of premature displacement of the external biliary drain is not uncommon, occurring in about $2 \%$ of cases $^{(7,67)}$. The occurrence of these complications after the scheduled removal of the drain, usually around the 21 st day after surgery, is exceptional and a possible downstream biliary obstruction should be suspected.

The premature displacement of the biliary drain occurred in four patients in our study. In two patients there were no postoperative complications. Another patient, after removal of the transcystic Kehr's drain, developed a fistula manifested by leakage of bile and sub-hepatic collection, kept under clinical control, with favorable evolution. In one patient there was premature displacement of the transcystic intra-cath (secured with two clips), evolving with a small exteriorized fistula.

In general, fistulas arising from inadvertent movement of the biliary drain are favorable, controlled conservatively ${ }^{(59)}$, including eventual endoscopic evaluation with performance of a papillotomy for biliary decompression ${ }^{(33)}$. However, in certain situations, there is a need for surgical re-intervention, which can also be performed by laparoscopy ${ }^{(8,36,68)}$.

\section{CONCLUSION}

The lithiasis in the main biliary tract was presented in an unsuspicious way by about one-third of the cases. The intra-operative cholangiography characterizes the calculi affection in the biliary tract and supports the decision of the conduct, especially in the choice of transcystic or transcholedochus routes. The videolaparoscopic surgical exploration of the biliary tract for treatment of choledocholithiasis achieves high success rates, around $80 \%$, and is associated with low morbidity.

Santos MA, Domene CE, Riccioppo D, Barreira L, Takeda FR, Pinotti HW. Coledocolitíase. Análise do tratamento videolaparoscópico. Arq Gastroenterol. 2012;49(1):41-51.

RESUMO - Contexto - Aproximadamente 9\% da população brasileira apresenta colecistolitíase e esta incidência aumenta significativamente com o envelhecimento. A coledocolitíase é encontrada em torno de 15\% destes pacientes, e de um terço a metade destes casos apresenta-se de maneira assintomática. Uma vez que a litíase do ducto biliar comum é caracterizada através de colangiografia intra-operatória, a exploração cirúrgica laparoscópica pode ser feita através da via transcística, ou diretamente através de coledocotomia. Objetivo - Avaliar os resultados do tratamento laparoscópico da coledocolitíase. Métodos - Setenta pacientes foram avaliados prospectivamente. Todos foram submetidos ao tratamento da coledocolitíase por videolaparoscopia, e as formas de exploração foram comparadas de acordo com os seguintes parâmetros: os critérios de sua indicação, o sucesso no clareamento da via biliar, complicações cirúrgicas. A exploração laparoscópica transcística foi favorecida quando não há critérios para a prática de coledocotomia primária, sendo estes litíase do ducto biliar proximal, cálculos grandes (mais de $8 \mathrm{~mm}$ ) ou calculose múltipla. Resultados - Verificouse que cerca de um terço dos doentes com coledocolitíase não mostraram qualquer expressão de fatores preditivos (antecedentes clínicos de icterícia e/ou pancreatite aguda, suspeita ultrassonográfica ou alterações de testes laboratoriais relacionados à coledocolitíase). A exploração transcística foi empregada em cerca de 50\% dos casos e a coledocotomia em cerca de 30\%. A depuração da via biliar através da laparoscopia foi alcançada em $80 \%$ dos casos. A exploração transcística, realizada sem fluoroscopia ou coledocoscopia, atingiu baixa taxa de sucesso (em torno de $45 \%$ ), sendo $10 \%$ desses casos com passagem transpapilar de cálculos com menos de $3 \mathrm{~mm}$. A exploração por coledocotomia, primária ou secundária, quando esta foi realizada após o insucesso da via transcística, mostrou alta taxa de sucesso (em torno de 95\%). Quando a indicação para coledocotomia era primária, a necessidade de visualização direta através da coledocoscopia para ajudar na remoção dos cálculos foi de $55 \%$. No entanto, quando foi realizada coledocotomia secundariamente, nas situações em que o diâmetro do ducto biliar comum foi maior do que 6 mm, o uso de coledocoscópio com o mesmo propósito foi necessário em cerca de $20 \%$ dos casos. Não houve mortalidade nesta série. Conclusão - A exploração laparoscópica da via biliar principal está relacionada com baixa taxa de morbidade. Portanto, o uso da laparoscopia para o tratamento da coledocolitíase depende dos critérios para a escolha do melhor acesso, tornando-se procedimento seguro, com resultados bastante satisfatórios.

DESCRITORES - Coledocolitíase. Laparoscopia. Colangiografia. 


\section{REFERENCES}

1. Amouyal P, Amouyal G, Lévy P, Tuzet S, Palazzo L, Vilgrain V, Gayet B, Belghiti J, Fékété F, Bernades P. Diagnosis of choledocholithiasis by endoscopic ultrasonography. Gastroenterology. 1994;106:1062-7.

2. Aroori S, Bell JC. Laparoscopic management of common bile duct stones: our initial experience. Ulster Med J. 2002;71:22-5.

3. Arregui ME. Exploração da via biliar principal. In: Coelho JCU, Marchesini JB Malafaia O, editores. Complicações da videocirurgia: da profilaxia ao tratamento. São Paulo: Medsi; 1995. p.243-66.

4. Bagnato VJ. Laparoscopic choledochoscopy and choledocholithotomy. Surg Laparosc Endosc. 1993;3:164-6.

5. Barkun AN, Barkun JS, Fried GM, Ghitulescu G, Steinmetz O, Pham C, Meakin JL, Goresky CA. Useful predictors of bile duct stones in patients undergoing laparoscopic cholecystectomy. Ann Surg. 1994;220:32-9.

6. Berci G, Morgenstein L. Laparoscopic management of common bile duct stones. A multi-institutional SAGES study. Society of American Gastrointestinal Endoscopic Surgeons. Surg Endosc. 1994;8:1168-75.

7. Berthou JCh, Dron B, Charboneau P, Moussalier K, Pellissier L. Evaluation of laparoscopic treatment of common bile duct stones in a prospective series of 505 patients: indications and results. Surg Endosc. 2007;21:1970-4.

8. Birth M, Ehlers KU, Delinikolas K, Weiser HF. Prospective randomized comparison of laparoscopic ultrasonography using a flexible-tip ultrasound probe and intraoperative dynamic cholangiography during laparoscopic cholecystectomy. Surg Endosc. 1998;12:30-6.

9. Boulay J, Schellenberg R, Brady PG. Role of ERCP and therapeutic biliary endoscopy in association with laparoscopic cholecystectomy. Am J Gastroenterol. 1992;87:837-42.

10. Cecconello I. Contribuição ao conhecimento da histopatologia do colédoco [dissertação]. São Paulo: Instituto Brasileiro de Estudos e Pesquisas de Gastroenterologia-IBEPEGE; 1979.

11. Champault $\mathrm{G}$. [Lithiasis of the commom bile duct (CBD) at the time of laparoscopic surgery. What strategy to follow?] Ann Chir. 1993;47:592-7.

12. Classen M, Safrany L. Endoscopic papillotomy and removal of gall stones. $\mathrm{Br}$ Med J. 1975;15:371-4.

13. Coelho JC, Bonilha R, Pitaki SA, Cordeiro RM, Salvalaggio PR, Bonin EA, Hahn CG, Soares RV, Milcheski DA. Prevalence of gallstones in a Brazilian population. Int Surg. 1999;84:25-8

14. Colcock BP, Perey B. Exploration of the common bile duct. Surg Gynecol Obstet. 1964:118:20-4.

15. Collins C, Maguire D, Ireland A, Fitzgerald E, O’Sullivan GC. A prospective study of common bile duct calculi in patients undergoing laparoscopic cholecystectomy: natural history of choledocholithiasis revisited. Ann Surg. 2004;239:28-33.

16. Cotton PB. Endoscopic management of bile duct stones (apples and oranges). Gut. 1984;25:587-97.

17. Cotton PB, Lehman G, Vennes J, Geenen JE, Russell RC, Meyers WC, Liguory C, Nickl N. Endoscopic sphincterotomy complications and their management: an attempt at consensus. Gastrointest Endosc. 1991;37:383-93.

18. Cotton PB. Endoscopic retrograde cholangiopancreatography and laparoscopic cholecystectomy. Am J Surg. 1993;165:474-8.

19. Crema E, Silva AA, Martins A Jr. Anastomose colédoco-duodenal por laparoscopia no tratamento da coledocolitíase. Boletim da FBG Gastren, edição especial, 1996.

20. Crema E, Camara CA, Pastore R, Teles CJ, Terra Júnior JA, Silva AG. Assessmen of positive perioperative cholangiography in patients undergoing elective laparoscopic cholecystectomy. Rev Col Bras Cir. 2010;37:403-6.

21. Csendes A. Common bile duct stones: introduction. World J Surg. 1998;22:1113.

22. D’Ippolito G, Galvão-Filho M, Jesus PEM, Woloske A, Borri ML. Colangiopancreatografia por ressonância magnética: aplicações clínicas. Radio Bras. 1998;31:149-56.

23. Danilewitz MD. Early postoperative endoscopic sphincterotomy for retained common bile duct stones. Gastrointest Endosc. 1989;35:298-9.

24. DePaula AL, Hashiba K, Bafutto M. Laparoscopic management of choledocholithiasis Surg Endosc. 1994;8:1399-403.

25. Domene CE, Ishigawa PS, Santo MA. Tratamento videolaparoscópico da coledocolitíase. ABCD Arq Bras Cir Dig. 1996;11:76

26. Domene CE, Santo MA, Volpe P. Laparoscopy choledochoduodenostomy [abstract]. Hepatogastroenterology. 1998;45:122.

27. Domene CE, Santo MA, Volpe P. Laparoscopy treatment of choledocholithiasis [abstract]. Hepatogastroenterology. 1998;45:126.

28. Edmundowicz SA. Common bile duct stones. Gastrointest Endosc Clin N Am. $1995 ; 5: 817-24$
29. Escudero-Fabre A, Escallon A Jr, Sack J, Halpern NB, Aldrete JS. Choledochoduodenostomy. Analysis of 71 cases followed for 5 to 15 years. Ann Surg. 1991;213:635-44.

30. Fink AS. ERCP or not ERCP? That is the question. Surg Endosc. 1993;7:375-6.

31. Fitzgibbons RJ Jr, Ryberg AA, Ulualp KM, Nguyen NX, Litke BS, Camps J, McGinn TR, Jenkins JX, Filipi CJ. An alternative technique for treatment of choledocholithiasis found at laparoscopic cholecystectomy. Arch Surg. 1995;130:638-42.

32. Franceschi D, Brandt C, Margolin D, Szopa B, Ponsky J, Priebe P, Stellato T, Eckhauser ML. The management of common bile duct stones in patients undergoing laparoscopic cholecystectomy. Am Surg. 1993;59:525-32.

33. Franklin ME Jr, Pharand D, Rosenthal D. Laparoscopic common bile duct exploration. Surg Laparosc Endosc. 1994;4:119-24.

34. Frazee RC, Roberts J, Symmonds R, Hendricks JC, Snyder S, Smith R, Custer MD, Stoltenberg P, Avots A. Combined laparoscopic and endoscopic management of cholelithiasis and choledocholithiasis. Am J Surg. 1993;166:702-6.

35. Gama-Rodrigues JJ, Bresciani C. Colecistectomia por videolaparoscopia. In: Mincis M, editor. Gastroenterologia e hepatologia: diagnóstico e tratamento. São Paulo: Lemos; 1997. p.815-26.

36. Gigot JF, Navez B, Etienne J, Cambier E, Jadoul P, Guiot P, Kestens PJ. A stratified intraoperative surgical strategy is mandatory during laparoscopic common bile duct exploration for common bile duct stones. Lessons and limits from an initial experience of 92 patients. Surg Endosc. 1997;11:722-8.

37. Hardy KJ. Gallstones and laparoscopic cholecystectomy: a consensus? Aust N Z J Surg. 1994;64:583-7.

38. Hauer-Jensen M, Karesen R, Nygaard K, Solheim K, Amlie EJ, Havig O, Rosseland AR. Prospective randomized study of routine intraoperative cholangiography during open cholecystectomy: long-term follow-up and multivariate analysis of predictors of choledocholithiasis. Surgery. 1993;113:318-23.

39. Hess W. Colecistectomías difíciles. In: Hess W. Enfermedades de las vías biliares y del páncreas. Barcelona: Editorial Científica Médica, 1963. p.379-84.

40. Horwood J, Akbar F, Davis K, Morgan R. Prospective evaluation of a selective approach to cholangiography for suspected common bile duct stones. Ann R Coll Surg Engl. 2010;92:206-10.

41. Houdart R, Perniceni T, Darne B, Salmeron M, Simon JF. Predicting common bile duct lithiasis: determination and prospective validation of a model predicting low risk. Am J Surg. 1995;170:38-43.

42. Huguier M, Bornet P, Charpak Y, Houry S, Chastang C. Selective contraindication based on multivariate analysis for operative cholangiography in biliary lithiasis. Surg Gynecol Obstet. 1991;172:470-4.

43. Hunter JG, Soper NJ. Laparoscopic management of bile duct stones. Surg Clin North Am. 1992;72:1077-97.

44. Kawai K, Akasaka Y, Murakami K, Tada M, Koli Y. Endoscopic sphincterotomy of the ampulla of Vater. Gastrointest Endosc. 1974;20:148-51.

45. Kazuhisa U, Hironobu O, Masaji T, Hiroyuki K, Manabu K, Masaki U, Hirok Y. Long-term prognosis after treatment of patients with choledocholithiasis. Ann Surg. 2003;238:97-102.

46. Khoo DE, Walsh CJ, Cox MR, Murphy CA, Motson RW. Laparoscopic common bile duct exploration: evolution of a new technique. Br J Surg. 1996;83:341-6.

47. Kullman E, Borch K, Lindström E, Svanvik J, Anderberg B. Management of bile duct stones in the era of laparoscopic cholecystectomy: appraisal of routine operative cholangiography and endoscopic treatment. Eur J Surg. 1996;162:873-80.

48. Kum CK, Goh PM. Preoperative ERCP in the management of common bile duct stones before laparoscopic cholecystectomy. Eur J Surg. 1996;162:205-10.

49. Lacitignola S, Minardi M, Palmieri R, Nigri A, Caliandro L, Rosellini A. A "one-stage" laparoscopic procedure for treating choledocholithiasis. JSLS 2005;9:419-21.

50. Lacitignola S, Minardi M. Management of common bile duct stones: a ten-year experience at a tertiary care center. JSLS. 2008;12:62-5.

51. Libanori HT, Domene CE, Nasi A, Pinotti HW. Routine laparoscopic cholangiography by a simple and successful technique. ABCD Arq Bras Cir Dig. 1995;10:47-50.

52. Liberman MA, Phillips EH, Carrol BJ, Fallas MJ, Rosenthal R, Hiatt J. Cost-effective management of complicated choledocholithiasis: laparoscopic transcystic duct exploration or endoscopic sphincterotomy. J Am Coll Surg. 1996;182:488-94.

53. Ludwig K, Bernhardt J, Lorenz D. Value and consequences of routine intraoperative cholangiography during cholecystectomy. Surg Laparosc Endosc Percutan Tech. 2002;12:154-9.

54. McSherry CK, Ferstenberg H, Calhoun WF, Lahman E, Virshup M. The natural history of diagnosed gallstone disease in symptomatic and asymptomatic patients. Ann Surg. 1985;202:59-63.

55. Monteiro-da-Cunha JE, Penteado S, Machado MCC, Pinotti HW. Coledocolitíase. In: Pinotti HW, Cecconello I, Gama-Rodrigues JJ, Habr-Gama A, Machado MCC, Saad WA, Faintuch J, Domene CE, editores. Tratado de clínica cirúrgica do aparelho digestivo. São Paulo: Atheneu; 1994. p.933-40. 
56. Morgenstern L, Berci G, Pasternak EH. Bile leakage after biliary tract surgery. A laparoscopic perspective. Surg Endosc. 1993;7:432-8.

57. Neuhaus H, Feussner H, Ungeheuer A, Hoffmann W, Siewert JR, Classen M. Prospective evaluation of the use of endoscopic retrograde cholangiography prior to laparoscopic cholecystectomy. Endoscopy. 1992;24:745-9.

58. NIH Consensus conference. Gallstones and laparoscopic cholecystectomy. JAMA. 1993;269:1018-24.

59. Paganini AM, Lezoche E. Follow-up of 161 unselected consecutive patients treated laparoscopically for common bile duct stones. Surg Endosc. 1998;12:23-9.

60. Perissat J, Huibregtse K, Keane FB, Russell RC, Neoptolemos JP. Management of bile duct stones in the era of laparoscopic cholecystectomy. Br J Surg. 1994;81:799-810.

61. Petelin JB. Laparoscopic approach to common duct pathology. Surg Laparose Endosc. 1991;1:33-41.

62. Petelin JB. Laparoscopic approach to common duct pathology. Am J Surg. 1993; 165:487-91.

63. Phillips EH, Rosenthal RJ, Carrol BJ, Fallas MJ. Laparoscopic trans-cystic duct common bile duct exploration. Surg Endosc. 1994;8:1389-94.

64. Phillips EH, Liberman M, Carrol BJ, Fallas MJ, Rosenthal RJ, Hiatt JR. Bile duct stones in the laparoscopic era. Is the preoperative sphincterotomy necessary? Arch Surg. 1995; 130:880-6.

65. Pinotti HW, Domene CE, Volpe P, Santo MA, Onari P. Formação do cirurgião em cirurgia laparoscópica do aparelho digestivo. Experiência de 1.818 intervenções sem acidentes e sem mortalidade. Rev Assoc Med Bras. 1999;45:337-41.

66. Quattlebaum JK Jr, Flanders HD. Laparoscopic treatment of common bile duct stones. Surg Laparosc Endosc. 1991;1:26-32.

67. Rhodes M, Sussman L, Cohen L, Lewis MP. Randomised trial of laparoscopic exploration of common bile duct versus postoperative endoscopic retrograde cholangiography for common bile duct stones. Lancet. 1998;351:159-61.

68. Robinson G, Hollinshead J, Falk G, Moulton J. Technique and results of laparoscopic choledochotomy for the management of bile duct calculi. Aust N Z J Surg. 1995;65:347-9.

69. Rosenthal RJ, Rossi RL, Martin RF. Options and strategies for the management of choledocholithiasis. World J Surg. 1998;22:1125-32.
70. Sakai P, Artifon ELA, Ishioka S. Uso de endoprótese biliar plástica na coledocolitíase. GED Gastroenterol Endosc Dig. 1999;18:233-6.

71. Santucci L, Natalini G, Sarpi L, Fiorucci S, Solinas A, Morelli A. Selective endoscopic retrograde cholangiography and preoperative bile duct stone removal in patients scheduled for laparoscopic cholecystectomy: a prospective study. Am J Gastroenterol. 1996;91:1326-30.

72. Savassi-Rocha PR, Ferreira JT, Diniz MT, Sanches SR. Laparoscopic cholecystectomy in Brazil: analysis of 33,563 cases. Int Surg. 1997;82:208-13.

73. Schwab G, Pointner R, Wetscher G, Glaser K, Foltin E, Bodner E. Treatment of calculi of the common bile duct. Surg Gynecol Obstet. 1992;175:115-20.

74. Shojaiefard A, Esmaeilzadeh M, Ghafouri A, Mehrabi A. Various techniques for the surgical treatment of common bile duct stones: a meta review. Gastroentero Res Pract. 2009 Aug 6. doi:10.1155/2009:840208.

75. Sjer AE, Boland DM, van Rijn PJ, Mohamad S. A decade of washing out common bile duct stones with papillary balloon dilatation as a one-stage procedure during laparoscopic cholecystectomy. Surg Endosc. 2010;24:2226-30.

76. Smith PC, Clayman RV, Soper NJ. Laparoscopic cholecystectomy and choledochoscopy for the treatment of cholelithiasis and choledocholithiasis. Surgery. 1992;111:230-3.

77. Speranzini MB, Castillo-Netto JM, Lima Jr SE. Defeitos na drenagem cirúrgica do colédoco. Rev Col Bras Cir. 1993;20:283-8.

78. Strasberg SM, Callery MP, Soper NJ. Laparoscopic surgery of the bile ducts Gastrointest Endosc Clin N Am. 1996;6:81-105.

79. Targarona EM, Bendahan GE. Management of common bile duct stones: controversies and future perspectives. HPB (Oxford). 2006;6:140-3.

80. Way LW, Admirand WH, Dunphy JE. Management of choledocholithiasis. Ann Surg. 1972;176:347-59.

81. Yeom DH, Oh HJ, Son YW, Kim TH. What are the risk factors for acute suppurative cholangitis caused by common bile duct stones? Gut Liver. 2010;4:363-7.

Received 26/7/2011. Accepted 31/8/2011. 